\title{
Digital Transformation of Law and Socio-Political Relations in the Eurasian Space - on the Example of the Russian Federation
}

\author{
Pavel Baranov ${ }^{1}$, Aleksei Mamychev ${ }^{2}$, Alexander Kim ${ }^{3}$, Tatyana Cherkasova ${ }^{4} \&$ Pavel Kolimbet $^{5}$ \\ ${ }^{1}$ Russian Presidential Academy of National Economy and Public Administration, Rostov-on-Don, Russia \\ ${ }^{2}$ Department of Theory and History of Russian and Foreign Law, Vladivostok State University of Economics \\ and Service, Vladivostok, Russia \\ ${ }^{3}$ Department of International Relations and Law, Vladivostok State University of Economics and Service, \\ Vladivostok, Russia \\ ${ }^{4}$ Dean of the Department of Political Science \& Department of Economic Theory and Entrepreneurship, \\ South-Russian Institute of Management of "The Russian Presidential Academy of National Economy and Public \\ Administration", Russia \\ ${ }^{5}$ Department of Political Science and Ethnopolitics, South-Russian Institute of Management of "The Russian \\ Presidential Academy of National Economy and Public Administration", Russia \\ Correspondence: Alexander Kim, Department of International Relations and Law, Vladivostok State University \\ of Economics and Service, Vladivostok, Russia. E-mail: kimaa9@gmail.com
}

$\begin{aligned} & \text { Received: October 11, } 2019 \quad \text { Accepted: November 6, } 2019 \quad \text { Online Published: November 28, } 2019 \\ & \text { doi:10.5539/jpl.v12n4p87 }\end{aligned} \quad$ URL: https://doi.org/10.5539/jpl.v12n4p87

The study was supported by the Russian Foundation for Basic Research as part of a scientific project № 19-011-31031

\begin{abstract}
The paper discusses the processes of digital transformation of the political and legal systems of society in the Eurasian space (for example, the Russian state-legal organization). The authors discuss the process of introducing digital technology and artificial intelligence into the enforcement process, as well as the impact of digital technology on the political process. The content explains that a virtual digital space is currently being formed and most public relations are starting to unfold in it. At the same time, it is shown that in cyberspace, traditional value- normative regulators do not have the necessary effectiveness in regulating the interaction of people, and between people and virtual digital actors. The necessity of creating new regulatory systems and safety standards is substantiated.
\end{abstract}

Keywords: power, state, artificial intelligence, politics, law, legal information systems, digital technologies

\section{Introduction}

The development of scientific and technological progress at all times acted not only as a driver for the development of the economic system of society, also as one of the factors changing political and legal system. Having a significant impact on the emergence of new areas of legal regulation, scientific and technological progress quite actively influenced legal instruments, the possibilities of its use and application, methods of legal impact. Scientific and technological progress changed the minds of people, contributed to the formation of a new type of legal and political culture, set entirely new tasks in the field of law-making and law enforcement, the changed role and nature of the development of political institutions.

The entry of society into the 21 st century was characterized with a revolutionary stage in the relationship between man and digital virtual space. Fundamentally new opportunities for human communications have appeared, as well as methods for producing, storing, processing and using huge amounts of information. The improvement of new computing communication technologies and methods of processing large amounts of data has led to the automation and robotization of various processes including production. It had a huge impact on changing the usual socio-political lifestyle, work and leisure. The rapid development of digital technology has changed the attitude towards the field of virtual entertainment and the use of cultural objects. In recent years, 
information technology has penetrated into all areas of public and social management. The digital revolution had great importance for the legal and political systems of society.

The rapid development of artificial intelligence systems, autonomous digital algorithms and robotic technologies has radically changed the landscape and the specifics of socio-legal ${ }^{1}$ and socio-political life ${ }^{2}$ of society. Today, the functioning legal institutions and legal complexes do not correspond to the nature and direction of the development of digital interaction in society, and the legal technique also requires improvement ${ }^{3}$. Socio-political communication, the forms and nature of the development of political relations ${ }^{4}$ are also radically changing, public-power interaction and the management system are transforming. In other words, law, politics, economics are "digitized" and "algorithmized". The image of the future law and order and the political system is rapidly changing. In addition, the processes of social and technical convergence are being activated, new actors (digital subjects, autonomous algorithms, unmanned vehicles, robotic devices, etc.) are coming to the forefront.

\section{Theoretical and Practical Problems}

Currently, there are no clear forecasts of the digital transformation of the socio-political life of society, law and legal technique are far behind the rapid development of digital and virtualized relationships. In this regard, the following problems are obvious today: firstly, ensuring effective regulation of relations based on modern digital technologies; secondly, socio-political governance, processes of interaction and political communication, which no longer rely on traditional political and legal forms, but form "new online communities", "virtualized identities", "interactive events", and etc.; thirdly, safeguarding and protecting universal human values, rights and freedoms in a digital algorithmic environment.

In addition, the complexity of the legal, value-normative and deontological regulation of digital technologies, autonomous algorithms, machines and robots is associated with their anonymous nature:

- on the one hand, they are the product and the object of human life, it is people who create, program and exploit these objects, put value-rational, moral and emotional-psychological components in the initial code of the latter (for example, machine learning, data array analysis and the formation of a meaningful decision are carried out on this basis);

- on the other hand, robotic technologies and digital algorithms are new "subjects of history", since they dramatically affect the interactions of people, they are intermediaries and participants in digital relationships, which today are developing a variety of processes (technological, economic, political, legal, etc.).

The foregoing is especially characteristic of the foundations of modern civilization (a system of humanistic values, the doctrine of human rights and freedoms, etc.) and future security systems in which these robotic technologies and autonomous digital algorithms are simultaneously objects that are associated with most risks and threats, and subjects that protect vital interests, infrastructure facilities, etc. ${ }^{5}$. Moreover, today people, things, algorithms, robots jointly form modes of functioning, participate in ensuring the rule of law and order, create specific relationships, forms and methods of interaction that have a completely different structure and character. All this is a challenge to the scientific community, which must carry out not only the conceptual and legal development of the categorical-conceptual apparatus, form legal definitions and doctrinal legal foundations for regulating the development, implementation and operation of innovative digital technologies, but also improvement the legal technique providing fixation and regulatory coding of relationships in the digital age.

\section{Methodological Research Base}

This study is based on some theoretical and methodological principles. First of all, this is the principle of complementarity of understanding the specifics of human interaction with digital technologies and robotic devices in the context of socio-political and socio-legal spheres, when, on the one hand, the existing political and legal institutions, structures and mechanisms largely determine human activity, set the norms and standards for the development and application of digital technologies, form the basic models for the use of robotic algorithms, determine the nature and direction of their use, and on the other hand, the effectiveness and sustainability of

\footnotetext{
${ }^{1}$ Baranov Pavel, Mamychev Aleksey, Mordovtsev Andrey and others (2018). Doctrinal-legal and ethical problems of developing and applying robotic technologies and artificial intelligence systems (using autonomous unmanned underwater vehicles. Herald of National Academy of Managerial Staff of Culture and Arts, № 2. pp. 465-472

${ }^{2}$ Mamychev A., Okorokov A., Bespalova T., Sviridkina E., Chertakova E. (2018). Civilizational modeling of political and legal development of the society in the XXI century. Revista Amazonia Investiga. № 15. Vol. 7. pp. 49 - 57

${ }^{3}$ Talapina E.V. (2018). Law and Digitalization: New Challenges and Prospects. Journal of Russian Law. No. 2. pp. 5-17

${ }^{4}$ Voinov D. (2007). Political ambitions of the Internet in Russia. Power. No. 2. pp. 88-91

${ }^{5}$ Greenfield A. (2018). Radical technology: the device of everyday life. Moscow, Publishing house "Delo" RANEPA,
} 
specific practices of application and interaction are determined with the "subjective factor".

The second important principle, the authors' reasoning is based on, is the principle of socio-political conventionality. According to the latter, the value-normative systems functioning in society, legal complexes and political institutions are of a concrete historical and social-communicative nature, which, by analogy, are transferred to structuring and streamlining in the field of human interaction and digital technologies. Therefore, when discussing the practice of implementation of digital technologies, it is necessary to take into account both this "transfer" and the convergence of traditional political and legal structures with new forms and methods of organizing innovative relations based on the latest achievements of scientific and technological progress.

The most important principle of the study of the development of digital transformation processes of law, politics, economics and other areas of society is the principle of integrity. It focuses on a systematic review of the interaction and interdependence of all elements of the political, legal and digital life of society, as well as a comprehensive accounting of value-normative, ethical and other elements, digital and technological standards in building new forms and practices of socio-political interaction.

The principle of reliability directs the authors' research to the matching of the findings and statements with the existing theoretical and methodological achievements of the social and humanitarian and technical sciences, analytical and empirical data, expert positions and technological developments.

we put a special focus of the present study on the methodological principle substantiated by Ann-Marie Mol, John Law, J. Butler and others ${ }^{6}$, according to it people, things, machines, digital technologies jointly form specific relations. Within such relations they are formed, mediated, objectified and essentially determined. This principle is called by researchers - "assembly method", it focuses on the study of how these specific relationships are created and how they unfold, and most importantly, in these relationships, technologies and machines are considered as integral "agents" (B. Latour) ${ }^{7}$, which form and influence practical activity and its character. Moreover, in the framework of these moving and constantly changing relations, there are always general conditions and forms of organization ("assembly forms") which are necessary for their existence and development, being multiple, they are preserved and transformed as a definite whole (I. Krasavin) ${ }^{8}$.

\section{Main Part}

Today, the phenomenon of the digital society is being actively researched by representatives of the humanities. There are new being developed ideas about the place and role of digital information in the lives of people and their groups, the degree of its impact on the levels of social communication, including in the political sphere, new opportunities in the field of political manipulation of public consciousness, etc. The interest of the problems of digitalization of the surrounding life is so great that it led to the use, of the term "digital ecosystem", which is perhaps not entirely correct in this case.

This term is used not only in science, but also in law-making, for example, in the "Strategy for the Development of the Information Society in the Russian Federation for 2017-2030"9. The latter circumstance clearly demonstrates that the world has really changed and the laws of digital virtual space begin to actively compete with the laws of nature, at least at the level of human consciousness.

In addition, there are active trends towards the full or partial transition of traditional elements of public and state life into digital virtual space. It is not only about changing the functional purpose of digital technologies, but also the emergence of a "new reality" in the form of the digital economy, digital law, digital politics, etc. ${ }^{10}$. There is also no doubt that modern digital technologies, creating the prerequisites for the transition to a new socio-economic development model, lead to a reformatting of the very method of legal regulation of social relations ${ }^{11}$.

Already today we are witnessing the formation of a new digital legal worldview, which differs significantly from

\footnotetext{
${ }^{6}$ Law J. (2015). After the method: mess and social science. Moscow, Publishing house of the Gaidar Institute; Delanda M. (2018). The new philosophy of society: Theory of assemblages and social complexity. Perm: Gil Press; Bennett J. (2018). Pulsating Matter: The Political Ecology of Things. Perm: Gil Press; Mol A. (2017). Multiple body: Ontology in medical practice. Perm: Gele Press.

${ }^{7}$ Latour B. (2014). Reassembly of the social: an introduction to actor-network theory. Moscow: Publishing House of Higher School of Economics; Latour B. (2018). Politics of nature. Moscow: Ad Margin Press,

${ }^{8}$ Krasavin I. (2013). Techne: community assembly. Moscow: armchair scientist,

${ }^{9}$ Decree of the President of the Russian Federation of 05.09.2017 No. 203 "On the Strategy of the Development of the Information Society in the Russian Federation for 2017 - 2030" Collection of legislation of the Russian Federation. 05/15/2017. No. 20. Art. 2901.

${ }^{10}$ ibid.

${ }^{11}$ Kartskhia A.A. (2017). The digital imperative: new technologies create a new reality. Copyright and related rights. No. 8. pp. 17 - 26.
} 
that which prevailed in previous periods of human history. Without diminishing the important role of law in the process of regulating new digital spheres of social relations, we should talk about law as one of the objects of the processes of "digitalization", leading to a change in its very form. It is no coincidence that many researchers note that digital technologies are actively changing the very image of law, indicators of its effectiveness and regulatory potential ${ }^{12}$.

First of all, it is necessary to pay attention to the question of what is the "written" positive law in the digital age. This is a fundamentally new digital form of law. In this case, we will talk not only about the direct carrier of information, but also about how the content of a normative legal act is perceived in the situation of its submission in electronic form in a legal reference system or database.

In accordance with the Constitution of the Russian Federation, Russia is a legal state (part 1 of article 1), in which the Constitution and federal laws have supremacy throughout its territory (part 2 of article 4$)^{13}$. In accordance with part 3 of article 15 unpublished laws are not applied, as well as any regulatory legal acts affecting the rights, freedoms and duties of a person and a citizen, if they are not published officially. These constitutional statements update the obligation of the state to provide complete and comprehensive information of the current state of legislation. However, modern digital technologies have provided an invaluable service in it.

So, for example, in accordance with article 4 of the Federal Law "On the Procedure of the Publication and Entry into Force of Federal Constitutional Laws, Federal Laws, Acts of the Chambers of the Federal Assembly" as the official publication of the federal constitutional law, federal law, act of the Chamber of the Federal Assembly shall be considered the first publication of its full text in the "Parliamentary Newspaper", "Russian newspaper" " Collection of the legislation of the Russian Federation "or the first placement (publication) on the "Official Internet portal of legal information" $"$.

In the original version of this law, there was no reference to the official Internet portal of legal information and appeared only in the 2011 edition. The Decree of the President of the Russian Federation of May 09, 2017 No. 203 "On the Strategy for the Development of the Information Society in the Russian Federation for 2017 - 2030 " already mentioned by us was first published on the official Internet portal, as well as many other regulatory legal acts. In this regard we note that the traditional "remark" of the search and reference system Consultant Plus that "the document was not published in this form" no longer corresponds to reality and requires clarification regarding the lack of an actual "paper edition". As for the current edition of the document posted on the "Official Internet portal of legal information", it is always present, along with regulatory legal acts that directly contain the changes. Thus, today there is no need to place the listed normative legal acts in paper periodicals and, possibly, in the near future such work will lose any sense at all.

It is not a secret that the information in paper periodicals does not make it possible to fully get acquainted with the current edition, for example, of a federal law, with the exception of the case of its initial publication. Many current federal laws have being changed dozens of times. As for the specific amendments, we can talk about hundreds times. The frequency of adoption of amendments to a particular law can be up to three to four per year. Thus, more than one hundred and forty amendments were adopted to the Federal Law "On General Principles of the Organization of Local Self-Government in the Russian Federation". The number of relevant amendments is unlikely to be countable. In this case, it is necessary to take into account the legal positions of the Constitutional Court of the Russian Federation, which have a certain legal force. It is impossible to imagine a modern person who, wishing to turn to the text of necessary federal law, will take a publication with its original version and several dozen publications containing federal laws on amendments to it. And this is a situation when, in any case, information about all changes have to be searched independently by accessing digital information databases. Thus, in the context of the senselessness and impracticality of use of official paper editions, their value as an "official source of publication" is nominal.

It should be noted that the practice of a separate edition of the current edition of the normative act in the "unofficial" edition has been preserved. Moreover, modern Russian publishers even offer special programs for

\footnotetext{
${ }^{12}$ Khabrieva T.Ya., Chernogor N.N. (2018). Law in digital reality. Journal of Russian law. No. 1. pp. 85-102

${ }^{13}$ Bedoeva Z.N. (2018). The role of information systems and technologies in ensuring state financial (budget) control. Financial Law. No 7. pp. $29-33$.

${ }^{14}$ Constitution of the Russian Federation (adopted by national vote 12/12/1993) (as amended by the Laws of the Russian Federation on amendments to the Constitution of the Russian Federation dated December 30, 2008 N 6-FKZ, dated 30.12.2008 N 7-FKZ, dated 05.02.2014 N 2 -FKZ, dated July 21, 2014 N 11-FKZ). Reference Legal System "Consultant Plus". [Electronic resource]. Access mode: http://www.consultant.ru/document/cons_doc_LAW_28399/
} 
the exchange with surcharge of outdated and irrelevant versions of regulatory legal acts for new and relevant ones. In our opinion, this is more related to the peculiarities of the pedagogical process, because the study of traditional paper is more suitable for the initial training of future lawyers. At the same time, the practice of including a large number of a legal "applications" in monographic publications has practically come to naught.

In our opinion, in modern conditions the publication of a normative act on the "Official Internet portal of legal information" is not only quite sufficient from a legal point of view, but also has much greater practical meaning in informing about the real state of the Russian legal system. Similarly, the situation is officially resolved at the level of regional legislation ${ }^{15}$. In this regard, we note that in the conditions of "optionality" of the formal procedure of publishing the text of a normative legal act in a "paper" official publication, the problem of access to the Internet by all citizens of the Russian Federation without exception, regardless of their place of residence, is particularly relevant, especially because access to relevant legal information resources is much simpler than to their paper versions.

An appeal to the bases of legal acts of the regional and local level, which is usually impossible in free versions of traditional reference and information systems, deserves special attention. The availability of up-to-date versions of legal acts of a regional and local level on special sites is especially important for ordinary citizens who, unlike practicing lawyers, cannot afford paid versions of regional and local databases, for example, the Consultant Plus system $^{16}$. It should be recognized that today the relevant work of public authorities with rare exceptions is not satisfactory.

However, it is reference and information systems that can be located both in the public domain on the Internet, on the computers of specific users or on the computer servers of organizations that deserve special attention as a source of up-to-date editions of regulatory legal acts. It's no secret that reference and information systems, for example, "Consultant Plus" or "Guarantor" 17 , are the most convenient source of obtaining the latest version of a regulatory legal act for lawyers and ordinary citizens. Paid versions of these programs provide users with qualitatively different opportunities for obtaining relevant legal information, raising the convenience of familiarizing themselves with legal material to a fundamentally different level.

However, reference and information systems been freely available on the Internet and located on the computers of specific users or on the server computers of organizations deserve special attention as a source of up-to-date editions of regulatory legal acts. It's no secret that reference and information systems, for example, "Consultant Plus" or "Garant" ", are the most convenient source of obtaining the latest version of a regulatory legal act for lawyers and ordinary citizens. Paid versions of these programs provide users with qualitatively different opportunities for obtaining relevant legal information, raising the convenience of familiarizing with legal material to a fundamentally different level. There is the possibility of viewing not only the current and inactive edition of the document, but also the formation of the corresponding comparative tables. The legal reference system is able to build an optimal system of direct and cross-links, using not only legal acts, but also decisions of the judicial authorities, as well as legal comments and legal literature. The systematization of search results may depend on several criteria pre-selected by the user.

A normative legal act no longer appears as a relatively independent and separate source of law, but as an integral part of the entire array of legal information in a complex system of direct and cross connections, clearly demonstrating its imperfection and, in some cases, showing possible contradictions to others normative legal acts. Analyzing the problem of a "different kind" that a normative legal act takes in its virtual systemic representation, we rightly pay attention to the way of the modern Russian constitution appears in the unity of its text, federal laws, federal constitutional laws, legal positions of the Constitutional Court of the Russian Federation and other judicial authorities, international legal acts, etc. ${ }^{19}$.

\footnotetext{
${ }^{15}$ Federal law 06/14/1994 No. 5-FZ (as amended on 07/01/2017) “On the procedure of publication and entry into force of federal constitutional laws, federal laws, acts of chambers of the Federal Assembly". Collection of legislation of the Russian Federation. 06/20/1994. No. 8. Art. 801; The regional law of the Rostov region 12/29/2003 No. 85-ZS (as amended on 08/02/2018) "On the procedure of publishing and entry into force of the Charter of the Rostov region, regional laws, resolutions of the Legislative Assembly of the Rostov region, legal acts of the Governor of the Rostov region and executive bodies authorities of the Rostov region (2004). Our time. No. 1. January 6,

${ }^{16}$ Law of the Republic of Tatarstan 08/06/2003 No. 27-ZRT (as amended on 09/29/2016) "On the procedure of the publishing and entry into force of the laws of the Republic of Tatarstan and other acts adopted by the state council of the Republic of Tatarstan and its presidium". Republic of Tatarstan. No. 160. 08/09/2003.

${ }^{17}$ Reference Legal System “Consultant Plus”. [Electronic resource]. Access mode: http://www.consultant.ru/

${ }^{18}$ Ibid.

${ }^{19}$ Kartskhia A.A. (2017). The digital imperative: new technologies create a new reality. Copyright and related rights. No. 8.
} 
However, as we have already noted, such a systematic representation of a normative legal act, in the case of the Constitution of the Russian Federation, clearly demonstrates not only all its "imperfections", but also the "imperfections" of the legislation specifying it. In our opinion, in some cases it can significantly reduce and underestimate the rich potential of the principles laid down in it, giving ultimately not always the correct idea of the initial constitutional model of development ${ }^{20}$.

In our opinion, legalization of reference legal systems should not be idealized. They have their own significant flaws often noticed by experienced users. In particular, considerable criticism is caused by the lack of integration of regional legislation into general arrays of legal information. However, under the conditions of a federal state-territorial structure and a significant number of subjects of the Russian Federation, the issues of correlation of federal and regional legal acts will always cause considerable difficulties. Full digitalization of the entire array of legal sources is fraught with certain risks ${ }^{21}$. In this regard, as the researchers note the level of user confidence in the texts posted in these special legal systems is not in doubt and discussion, while no one can guarantee the exact correspondence of the digital copy to the original ${ }^{22}$.

Let us comment that it's possible to speak about traditional "paper" sources of public law in a similar way. Unfortunately, how the disciplinary responsibility of the employees of the "official" public legal information portals and their "colleagues" from the reference and search systems "Consultant Plus" and "Garant" can be discussed only theoretically. It is impossible to exclude conscious "wrecking" of their hooligan or any selfish considerations, including in the process of so-called hacker attacks. We can only imagine the possible risks and threats posed by the deliberate distortion of the "legal space" of Russia in information banks and systems. The issue of legal liability for intentional or unintentional inaccurate presentation of normative acts or materials of judicial practice may be one of the interesting areas of scientific research.

\section{Findings}

In conclusion, we note the existing reference and information systems have an exceptionally positive impact not only on law enforcement processes, but also on law-making processes. A fairly coherent legal data system created thanks to reference and information systems let us suggest that this is exactly what the digital model of legal regulation of the future will look like, minus all the imperfections and contradictions inherent in modern legal systems. We are talking about a far-reaching prospect of creating a unified legal array with all the attributes of harmony and consistency, due to the active use of artificial intelligence in its creation.

In continuation of the topic, we could talk about the introduction of digital technologies and artificial intelligence in the law enforcement process, especially since some steps in this direction have already been taken and human participation in making individual enforcement decisions is formal. The concept of digital technologies as exclusively auxiliary is a thing of the past. The first place is the understanding of virtual digital space as a "territory" where a person spends a significant part of his life with "artificial intelligence". A territory where traditional human laws must be largely adapted and in many cases new ones invented.

\section{Copyrights}

Copyright for this article is retained by the author(s), with first publication rights granted to the journal.

This is an open-access article distributed under the terms and conditions of the Creative Commons Attribution license (http://creativecommons.org/licenses/by/4.0/).

\footnotetext{
${ }^{20}$ Information and legal portal "Garant". [Electronic resource]. Access mode: https://www.garant.ru/

${ }^{21}$ The constitutional and legal policy of modern Russia: ideas, priorities, values, directions: monograph / P.P. Baranov, A.I. Ovchinnikov, A.Yu. Mamychev [et al.]. (2019). Moscow: RIOR: INFRA-M,

${ }^{22}$ Pavel Baranov, Aleksey Mamychev, Andrey Plotnikov, Svetlana Vershinina, Tatyana Mychak (2018). Interactive communication and modernization technologies of governmental administration in modern society: main contradictions and direction of development. Herald NAMSCA. № 2. p. 458-464.
} 